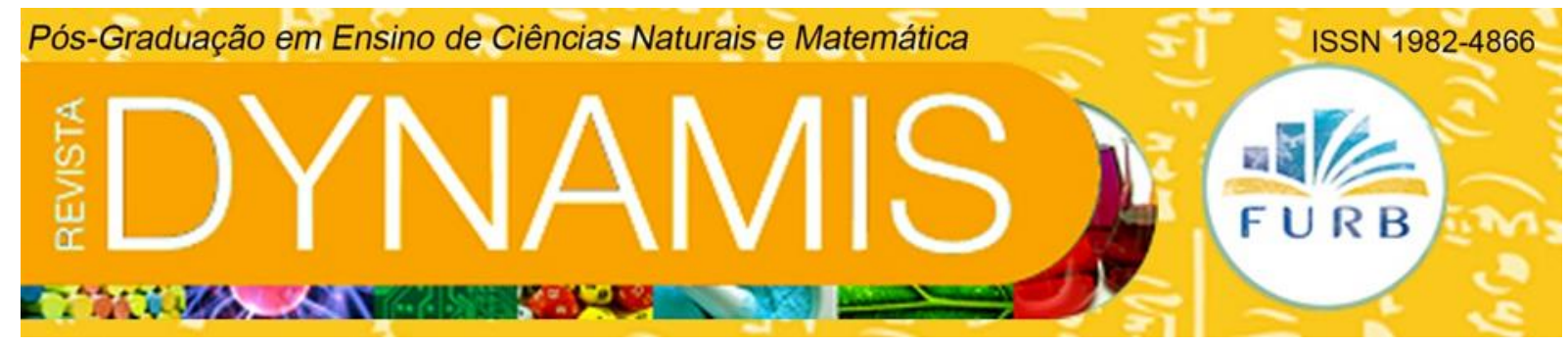

\title{
MODELAGEM MATEMÁTICA NA SALA DE AULA: UMA ABORDAGEM INTERDISCIPLINAR NO ENSINO DE FÍSICA
}

Mathematical Modeling in the classroom: a interdisciplinary approach in Physics Teaching

\footnotetext{
Maria Rosana Soares

Doutoranda pelo Programa de Estudos Pós-Graduados em Educação Matemática Bolsista - Coordenação de Aperfeiçoamento de Pessoal de Nível Superior Pontifícia Universidade Católica de São Paulo (PUC/SP) maryrosana@uol.com.br
} 


\title{
Resumo
}

A Modelagem ${ }^{1}$ permite ser trabalhada de forma interdisciplinar ao relacionar as pesquisas específicas do tema escolhido e conceitos de Física e/ou de Matemática a partir da realidade. Este artigo objetiva apresentar e discutir as contribuições obtidas por meio das atividades de Modelagem sobre energia elétrica no Ensino de Física. Isso foi aplicado em colégios estaduais, Paraná: $1^{\circ}$ ano do Ensino Médio (2010) e $1^{\circ}$ ano do Curso Integrado de Agropecuária (2010) pesquisadora atuava como docente. $\mathrm{O}$ estudo se orienta a partir de pesquisas bibliográficas e práticas; metodologicamente, faz uso da pesquisa qualitativa e do tipo estudo de caso, em que as coletas de dados se deram por meio da observação, intervenção na pesquisa, dados extraídos dela e questionário pós-teste: dados retirados da COPEL2, anotações, registros e materiais elaborados pelos sujeitos. Portanto, as atividades desenvolvidas de Modelagem propiciaram contribuições aos sujeitos em termos sociais, ambientais, financeiros e conceitos estudados e pesquisados, pois eles evidenciaram a relevância do uso racional da energia elétrica e seu uso consciente cotidianamente.

Palavras-chave: Modelagem Matemática. Ensino de Física. Energia Elétrica. Ensino e Aprendizagem. Interdisciplinar.

\begin{abstract}
The Modeling allows to be worked in a interdisciplinary way by relating the specific researches of the chosen topic and concepts of Physics and/or Mathematics from reality. This article aims to present and discuss the contributions obtained through modeling activities about electricity in the Physics Teaching. This was applied in state colleges, Paraná: 1st year of high school (2010) and 1st year Integrated Agricultural Course (2010) - researcher worked as a teacher. The study is guided by library research and practices; methodologically, it makes use of the qualitative research and the type of case study, and its data collection were done through by observation, intervention research, data extracted from it and posttest questionnaire: data from the COPEL, notes, records and materials produced by the subjects. Therefore, the activities of Modeling have provided contributions to the subjects in social, environmental, financial terms and concepts studied and researched, as they have evidenced the importance of the rational use of electricity and its conscious daily use.
\end{abstract}

Keywords: Mathematical Modeling. Physics Teaching. Electricity. Teaching and learning. Interdisciplinary.

\footnotetext{
${ }^{1}$ A fim de evitar repetições textuais, usaremos indistintamente os termos Modelagem e Modelagem Matemática.

2 COMPANHIA PARANAENSE DE ENERGIA (COPEL). 2010. 2014. Residencial: consumo de energia. Disponível em: <http://www.copel.com/hpcopel/residencial/consumoEnergia.jsp>. Acesso em: 04 mar. 2014.
} 


\section{INTRODUÇÃO}

Uma das Ciências mais antigas, a Física, é responsável por grande parte do desenvolvimento científico alcançado pela humanidade (BONJORNO; CLINTON, 2005, p. 15). "A Física ensinada atualmente, no ensino médio brasileiro, apresenta-se carente de perspectivas que a elimine [sic] da condição de disciplina cujos índices de reprovação lideram o ranking nas escolas" (ROSA; ALVES FILHO, 2012, p. 8, grifo dos autores). Nela, o conceito de energia elétrica se insere no tópico chamado eletromagnetismo. Este tema foi motivação para desenvolver este trabalho, pois a oferta de energia elétrica já é alarmante e no futuro essa tendência pode tornar-se mais evidente ainda. No âmbito nacional ou não, há investigações por alternativas para favorecer a eficácia dos sistemas de energia e a redução de seu consumo. Isso destaca a necessidade de novos setores de atuação, seja na obtenção de fontes energéticas ou na racionalização do consumo. Desse modo, o uso consciente de energia se torna uma questão vital para se prevenir o caos no sistema energético e com isso é relevante a conscientização dos estudantes e de outras pessoas para o uso racional dessa fonte de energia.

Bassanezi (2009, p. 16) infere que: “As vantagens do emprego da modelagem em termos de pesquisa podem ser constatadas nos avanços obtidos em vários campos como a Física, a Química, a Biologia e a Astrofísica, entre outros. A Modelagem pressupõe a multidisciplinaridade", a interdisciplinaridade ou a transdisciplinaridade. Bassanezi (2009, p. 38) diz que "A Modelagem no ensino é apenas uma estratégia de aprendizagem, onde o mais importante não é chegar imediatamente a um modelo bem-sucedido mas, caminhar seguindo etapas onde o conteúdo matemático vai sendo sistematizado e aplicado". Gaspar (2010, p. s. 14-15) infere que a linguagem física pode ser expressa por cinco categorias: conceitos, princípios, leis, modelos e teorias. Na sua concepção, o conceito físico é a representação de um objeto, pelo pensamento, por meio de suas características gerais; por exemplo, energia, comprimento, massa, tempo, eletricidade, velocidade e temperatura.

No ensino de Física, a Modelagem Matemática é uma abordagem de ensino e de aprendizagem que envolve um processo dinâmico que propicia investigar, problematizar e transformar as situações, os fenômenos ou os dados da realidade em expressões físicas que fazem uso da matemática, ou seja, em modelos físicos e/ou matemáticos. Tal processo não objetiva obter um modelo que faça uma representação total da realidade, mas sim parcial, que permita realizar e explorar as formulações e as matematizações de problemas reais ou físicos, bem como desenvolver os modelos físicos e aplicar os conceitos da Física, proporcionando, simultaneamente, o entendimento do papel sociocultural dessa disciplina.

Sobre a Modelagem no Ensino de Física há pesquisas feitas, como as de Daroit, Haetinger e Dullius (2009), Brandão, Araujo e Veit (2014), Batista e Fusinato (2015) e Setti, Schwertner, Deparis, Turra e Vertuan (2016), os quais expõem que o seu uso em sala de aula pode favorecer o ensino e aprendizagem dessa disciplina. Entre as possibilidades, há a multidisciplinar (uma abordagem que solicita a obtenção de informações para uma ou mais disciplinas e/ou ramos de conhecimento, sem interligações e modificações em seus aspectos conceituais e processuais); a interdisciplinar (uma abordagem que ocorre a partir de interações recíprocas entre duas ou mais disciplinas e/ou campos de conhecimento, com conexões e relações em seus aspectos conceituais e processuais, resultando a interdisciplina); ou a transdisciplinar (uma abordagem que sucede a partir da interações globais entre várias disciplinas e/ou ramos de conhecimento, além da abordagem interdisciplinar, com cooperações e profundidades superando seus aspectos conceituais e processuais, resultando a macrodisciplina), segundo os objetivos propostos. Aqui, empregamos a interdisciplinaridade "como uma possibilidade de, a partir da investigação de um objeto, conteúdo, tema de estudo ou projeto" (TOMAZ; DAVID, 2013, p. 26) visando "promover atividades escolares que 
mobilizam aprendizagens vistas como relacionadas, entre as práticas sociais das quais alunos e professores estão participando, incluindo as práticas disciplinares" (TOMAZ; DAVID, 2013, p. 26). Ela possibilita efetuar relações entre as pesquisas específicas do tema escolhido e os conceitos de Física e/ou de Matemática a partir da realidade, tendo como propósitos comuns os processos de ensino e de aprendizagem, minimizando ou eliminando as abordagens e as barreiras tradicionais de ensino.

No processo de ensino e aprendizagem de Física, isso é alegado em diversos estudos ou pesquisas realizadas que visam propiciar subsídios à prática docente, com o objetivo de tornar as aulas de Física investigadoras e motivadoras para os estudantes ao se explorar a matéria de modo claro, com significado, aplicação e contextualização sobre e/ou por meio de situações ou problemas reais e/ou físicos. Esse é o motivo de se apresentarem e se discutirem as contribuições obtidas por meio das atividades de Modelagem sobre energia elétrica no Ensino de Física - as quais foram desenvolvidas pela Secretaria da Educação do Paraná (SEED) e efetivadas em dois colégios estaduais do Paraná: $1^{\circ}$ ano do Ensino Médio (2010) e $1^{\circ}$ ano do Curso Integrado de Agropecuária (2010), nos quais a pesquisadora atuava como docente.

\section{FUNDAMENTOS TEÓRICOS}

\subsection{O ENSINO DE FÍSICA}

O ensino da Física permite aos estudantes motivar, realizar e explorar seus pensamentos, criatividades, autonomias, curiosidades, criticidades, linguagens, formulações e resoluções de problemas do dia a dia, transferindo-as para a linguagem física, que faz uso da matemática. Consequentemente, pode favorecê-los no sentido de que aprimorem suas competências, apliquem os conceitos físicos a partir de problemas da realidade, trabalhem agrupados em sala de aula, adquiram conhecimentos e troquem experiências de aprendizado. Para tanto, há alguns desafios a serem superados, como inferem Daroit et al. (2009, p. 1):

\footnotetext{
[...] o aspecto mais importante está na forma que os professores procedem dentro da sala de aula: os conceitos são apresentados aos estudantes de forma estanque, sem relação com os aspectos que envolvem a realidade, não levando em conta o entendimento dos fenômenos que ocorrem no dia-a-dia e ainda, o mais grave, a grande maioria dos professores detém-se à matematização da Física, desconsiderando o caráter revolucionário dos seus conceitos e leis, como se o resultado numérico obtido através de fórmulas elaboradas fosse o objetivo final do estudo.
}

O ensino de Física, em diversas realidades, vem sendo desenvolvido de forma metódica, sistemática e com tratamento estanque, em que os estudantes são inertes e acríticos e o(a) docente é detentor(a) do conhecimento, e estes(as) focam o resultado encontrado e não as explorações de competências e dos conhecimentos prévios dos estudantes, bem como as aplicações reais dos conceitos físicos no processo de ensino e aprendizagem. Diante disso, Batista e Fusinato (2015, p. 87) afirmam que:

Uma proposta para novas metodologias consiste em criar novos ambientes de aprendizagem em que a participação do professor seja de orientador das atividades e não de detentor do conhecimento - e em que os alunos tenham a liberdade de propor, 
desenvolver, criar, elaborar, modelar as ideias na construção dos conhecimentos, não sendo estes meros receptores de informação.

Para isso, é preciso incorporar e explorar algumas abordagens pedagógicas que possibilitem visar o ensino e aprendizagem de Física, como, por exemplo, a Modelagem.

\subsection{A MODELAGEM MATEMÁTICA NO ENSINO DE FÍSICA}

No processo de ensino e aprendizagem, "Podemos dizer que, de modo geral, o termo 'modelagem matemática' refere-se à busca de uma representação matemática para um objeto ou um fenômeno que pode ser matemático ou não" (ALMEIDA; FERRUZZI, 2009, p. 120). A Modelagem Matemática "[...] é um ambiente de aprendizagem no qual os alunos são convidados a problematizar e investigar, por meio da matemática, situações com referência na realidade" (BARBOSA, 2003, p. 69, grifos do autor). No ensino de Física, a Modelagem pode ser entendida como uma abordagem de ensino ou abordagem científica. Nele, ela propicia expressar os fenômenos e os problemas reais em modelos físicos e/ou matemáticos, desenvolvendo a aprendizagem matemática e/ou física conforme os objetivos a serem atingidos. Na Modelagem, investiga-se e expressa-se parte da realidade por meio de relações matemáticas e/ou físicas, explorando-se as capacidades e conhecimentos dos estudantes.

Uma atividade de Modelagem proporciona pesquisar, analisar e verificar problemas da realidade, em que se desenvolve sua formulação e sua resolução em linguagem matemática e/ou física, possibilitando aos(às) estudantes a atribuição de sentidos e a construção de significados. O modelo matemático é resultante da exploração, da exploração e da transformação de problematizações das situações, dados ou fenômenos (reais, físicos e/ou matemáticos), e por meio dele, são realizadas a organização, a resolução, a representação, a solução e a explicitação de matematizações dos problemas formulados a partir da realidade, visando o ensino e a aprendizagem. Tal modelo pode ser expresso por meio de um conjunto de símbolos, estruturas e relações físicas e/ou matemáticas: gráficos, tabelas, funções, representações físicas, expressões matemáticas, sistemas, equações, figuras geométricas, diagramas e representações estatísticas, entre outros conceitos físicos, matemáticos e/ou estatísticos. Ele é desenvolvido na própria Física por excelência, bem como em outras áreas e/ou disciplinas independentes que fazem uso da física, da matemática e de seus modelos, como Administração, Agronomia, Ciências, Engenharias, Estatística, Física, Geografia, Meteorologia, Medicinas e Tecnologias.

Em vista disso, Batista e Fusinato (2015, p. 88) propõe "duas possibilidades pedagógicos [sic] no ensino de física para uma aprendizagem efetiva pelos alunos": “(1) a contextualização do fenômeno a ser estudado; (2) a organização de um ambiente de aprendizagem norteado pela modelagem matemática" (BATISTA; FUSINATO, 2015, p. 88). Esses autores esclarecem que:

[...] a utilização da modelagem matemática no ensino de física favorece a desmistificação de que essa é uma disciplina difícil onde se devem decorar fórmulas para serem utilizadas em problemas nos quais é possível extrair os dados necessários, sem a menor preocupação quanto à sua compreensão. Aqui se espera que essas tais "fórmulas" passem a ter um significado para o aluno na medida em que estas são construídas por meio de relações e significados advindos do experimento realizado e/ou das discussões subsequentes. (BATISTA; FUSINATO, 2015, p. 88). 
A Modelagem tem por interesse estruturar e traduzir fatos empíricos de diferentes contextos sociais, permitindo modelar e evidenciar parte da realidade por meio dos conceitos físicos e/ou matemáticos já conhecidos, bem como dos novos que serão discutidos e apreendidos. Conforme progride o desenvolvimento da Física e da Matemática, a Modelagem visa obter a compreensão da realidade por meio da implantação e do aprimoramento da relação entre as pesquisas concretas, os(as) estudantes, o(a) docente, a instituição, os modelos físicos e/ou matemáticos e a aprendizagem. Ela é uma alternativa pedagógica que propicia apresentar a Física no cotidiano, propiciando análises e reflexões referentes aos seus usos nos contextos sociais e culturais, nos fenômenos e em várias situações reais, permitindo investigá-la, interpretá-la e explicá-la diante dos problemas formulados da realidade. Ela habilita a expressão dos fenômenos e problemas reais em modelos físicos, desenvolvendo a aprendizagem.

\section{PROCEDIMENTOS METODOLÓGICOS}

Este artigo é resultado de duas atividades de Modelagem aplicadas num $1^{\circ}$ ano de Ensino Médio e num $1^{\circ}$ ano do Curso Integrado de Agropecuária, ambos em Colégios Estaduais do Paraná, Brasil, na disciplina de Física, no horário normal de aulas, excetuando-se o intervalo de férias e a semana de avaliação. Em cada colégio, as atividades aplicadas apresentaram um total de seis etapas organizadas e fizeram uso de 16 horas-aula (h/a) em sala de aula e $1 \mathrm{~h} / \mathrm{a}$ em trabalhos extraclasse, realizando uma articulação nessas duas situações. No $1^{\circ}$ ano de Ensino Médio, havia 30 estudantes regularmente matriculados; entretanto, em virtude de desistências e/ou faltas provisórias de alguns, participaram efetivamente no mínimo 27 estudantes, ao passo que o $1^{\circ}$ ano do Curso Integrado de Agropecuária se valeu de 31 sujeitos regularmente matriculados e da participação ativa de aproximadamente 25 .

Para realizar as atividades de Modelagem no Ensino de Física nos dois colégios apresentados anteriormente, os estudantes dispuseram de autonomia para se organizar e se subdividiram em seis grupos com número de estudantes de forma equivalente: G1, G2, G3, G4, G5 e G6, em que foram identificados por: AG1, AG2, AG3, AG4, AG5 e AG6. Nesse contexto, G1, por exemplo, quer dizer "primeiro grupo", AG expressa "estudantes agrupados" e AG1 simboliza os "estudantes ou universitários do primeiro grupo", ao passo que P significa "professora" ou "pesquisadora" em ação. Ademais, nas seis etapas realizadas, os estudantes receberam materiais impressos visando propiciar estímulos, indagações e discussões no processo de ensino e aprendizagem de Física. Também a maioria das atividades propostas foi realizada pelos estudantes especialmente por escrito, assim como por meio do computador/notebook, pessoal ou da professora pesquisadora, ou do laboratório de informática.

A coleta de dados foi investigada e organizada pela pesquisadora e abordada juntos aos AG tanto nas discussões teóricas quanto nas atividades práticas em devido suas inexperiências e conhecimentos escassos em relação ao assunto, bem como visando incentivá-los a aprender conceitos físicos por meio da Modelagem. Para fins de aclarações, tais atividades práticas fizeram uso de dados e informações da COPEL, conforme referenciados neste artigo.

Para tanto, a presente proposta fez uso das abordagens qualitativa, bibliográfica, aplicada e interpretativa conforme as concepções de Lincoln e Guba (1985), Miles e Huberman (1994), André (1998), Bogdan e Biklen (1994), Denzin e Lincoln (2006) e Lüdke e André (2012). Denzin e Lincoln (2006, p. 23) aclaram sobre a pesquisa de natureza qualitativa: 
A palavra qualitativa implica uma ênfase sobre as qualidades das entidades e sobre os processos e os significados que não são examinados ou medidos experimentalmente (se é que são medidos de alguma forma) em termos de quantidade, volume, intensidade ou frequência. Os pesquisadores qualitativos ressaltam a natureza socialmente construída da realidade, a íntima relação entre o pesquisador e o que é estudado, e as limitações situacionais que influenciam a investigação. Esses pesquisadores enfatizam a natureza repleta de valores da investigação. Buscam soluções para as questões que realçam o modo como a experiência social é criada e adquire significado.

Para Denzin e Lincoln (2006, p. 17) “[...] a pesquisa qualitativa envolve uma abordagem naturalista, interpretativa, para mundo, o que significa que seus pesquisadores estudam as coisas em seus cenários naturais", em que tentam "entender, ou interpretar, os fenômenos em termos dos significados que as pessoas a eles conferem" (DENZIN; LINCOLN, 2006, p. 17). Ela valoriza o desenvolvimento do estudo, e investiga, explora, analisa, interpreta e entende seu ambiente natural de aprendizagem e seu processo realizado nas atividades de Modelagem. Já a bibliográfica e a interpretativa permitem apresentar e discutir algumas orientações que a Modelagem como estratégia de ensino e aprendizagem pode proporcionar aos estudantes de Física. A aplicada permite explicitar o papel da Física na sociedade por meio de uma prática de Modelagem em sala de aula, em ambientes extraclasse e em uma combinação disso.

$\mathrm{Na}$ acepção de Denzin e Lincoln $(2006$, p. 17) "a pesquisa qualitativa envolve o estudo do uso e a coleta de uma variedade de materiais empíricos", por exemplo, "estudo de caso; experiência pessoal; introspecção; história de vida; entrevista; artefatos; textos e produções culturais; textos observacionais, históricos, interativos e visuais" (DENZIN; LINCOLN, 2006, p. 17), os quais "descrevem momentos e significados rotineiros e problemáticos na vida dos indivíduos" (DENZIN; LINCOLN, 2006, p. 17). Isso envolveu uma análise do tipo estudo de caso, que "visa conhecer uma entidade bem definida como uma pessoa, uma instituição, um curso, uma disciplina, um sistema educativo, uma política ou qualquer outra unidade social" (PONTE, 2006, p. 2). Assim, “O seu objectivo é compreender em profundidade o 'como' e os 'porquês' dessa entidade, evidenciando a sua identidade e características próprias, nomeadamente nos aspectos que interessam ao pesquisador" (PONTE, 2006, p. 2).

$\mathrm{O}$ estudo de caso trata de investigar alguma natureza empírica focando o aprofundamento e o entendimento de certa entidade, situação, problema ou fenômeno em algum contexto da realidade. Nele, visa-se explorar e analisar uma investigação conforme as especificidades, as potencialidades, a natureza, o desenvolvimento e/ou o aprimoramento dos conhecimentos prévios ou não, as estratégias abordadas, os processos realizados e a compreensão profunda do contexto estudado ou pesquisado. Na sequência, há um quadro aclarando como foram organizadas as atividades de Modelagem Matemática realizadas no ensino de Física:

\section{Quadro 1 - Organização da Proposta de Modelagem}

\begin{tabular}{|c|l|}
\hline & $\begin{array}{l}\text { - Investigar as contribuições que a Modelagem Matemática pode proporcionar aos } \\
\text { estudantes de duas turmas do Ensino Médio de Física, usando o tema energia } \\
\text { Objetivos das } \\
\text { atividades de } \\
\text { Modelagem }\end{array}$ \\
$\begin{array}{l}\text { - Analisar o consumo de energia elétrica dos principais equipamentos } \\
\text { eletroeletrônicos utilizados nas residências dos estudantes; } \\
\text { - Analisar o custo mensal e a redução do consumo de energia elétrica residencial. }\end{array}$ \\
\hline
\end{tabular}




\begin{tabular}{|c|c|}
\hline $\begin{array}{l}\text { Natureza da } \\
\text { Pesquisa }\end{array}$ & $\begin{array}{l}\text { De acordo com Lincoln e Guba (1985), Miles e Huberman (1994), André (1998), } \\
\text { Bogdan e Biklen (1994), Denzin e Lincoln (2006) e Lüdke e André (2012): } \\
\text { qualitativa, bibliográfica, aplicada e interpretativa. }\end{array}$ \\
\hline $\begin{array}{l}\text { Por que a } \\
\text { pesquisa } \\
\text { qualitativa é } \\
\text { aplicada? }\end{array}$ & $\begin{array}{l}\text { - Apresenta-se a Física presente no cotidiano relacionando a teoria à prática; } \\
\text { - Investigam-se as situações-problema da realidade; } \\
\text { - Compreende-se a natureza, a origem dos problemas e suas soluções. }\end{array}$ \\
\hline $\begin{array}{l}\text { Por que a } \\
\text { pesquisa } \\
\text { qualitativa é } \\
\text { interpretativa? }\end{array}$ & $\begin{array}{l}\text { - Prioriza o ambiente natural de aprendizagem, o processo de ensino e } \\
\text { aprendizagem; } \\
\text { - Visa interpretar e entender as experiências, conhecimentos, concepções, } \\
\text { indagações e compreensões dos sujeitos e os dados obtidos na aplicação da } \\
\text { Modelagem. }\end{array}$ \\
\hline $\begin{array}{l}\text { Procedimentos } \\
\text { da pesquisa }\end{array}$ & $\begin{array}{l}\text { Observação, intervenção na pesquisa, questionário pós-teste, dados retirados da } \\
\text { pesquisa, como anotações e registros de participação dos sujeitos, e dados extraídos } \\
\text { da Companhia Paranaense de Energia Elétrica (COPEL). }\end{array}$ \\
\hline $\begin{array}{l}\text { Sujeitos da } \\
\text { pesquisa }\end{array}$ & $\begin{array}{l}\text { - Estudantes do } 1^{\circ} \text { ano do Curso Integrado de Agropecuária; com } 31 \text { sujeitos } \\
\text { regularmente matriculados e participação efetiva de em torno de } 25 \text {; } \\
\text { - Estudantes do } 1^{\circ} \text { ano do Ensino Médio; com } 30 \text { sujeitos regularmente matriculados } \\
\text { e participação efetiva de em torno de } 27 \text {. }\end{array}$ \\
\hline $\begin{array}{l}\text { Onde foi } \\
\text { aplicada }\end{array}$ & $\begin{array}{l}\text { - Colégio Estadual Agrícola Mohamad Ali Hamzé, Cambará-PR (CEA); período } \\
\text { vespertino; } \\
\text { - Colégio Estadual Professor Silvio Tavares - Ensino Fundamental, Médio, } \\
\text { Profissional e Normal, Cambará-PR (CES); período matutino. }\end{array}$ \\
\hline $\begin{array}{l}\text { Quando foi } \\
\text { desenvolvida }\end{array}$ & Segundo semestre de 2010, nos dois colégios citados acima. \\
\hline Duração & $\begin{array}{l}\text { Para o desenvolvimento da pesquisa, cada instituição de ensino fez uso de: } \\
\text { - Aulas regulares - } 16 \text { horas-aula total; utilizando, em média, } 2 \text { horas-aula } \\
\text { semanalmente (cerca de } 100 \text { minutos); } \\
\text { - Atividades extraclasse }-1 \text { hora-aula total (desenvolvimento da Modelagem } \\
\text { Matemática em ambientes extraclasse - DMME). }\end{array}$ \\
\hline
\end{tabular}

Fonte: Elaborado pela autora

O objetivo proposto foi atingido a partir de pesquisas bibliográficas e práticas, empregando a análise do tipo estudo de caso e a abordagem qualitativa de cunho interpretativo, em que as coletas de dados foram obtidas por meio da observação, da intervenção na pesquisa, do questionário pós-teste, dados retirados da Companhia Paranaense de Energia Elétrica (COPEL) e dos dados extraídos da pesquisa: anotações e registros de participação dos sujeitos.

\section{ATIVIDADES DE MODELAGEM SOBRE ENERGIA ELÉTRICA}

De acordo com Bassanezi (2009) e Barbosa (1999, 2001, 2003), em síntese, Soares (2012a, 2012b) sugere que as atividades de Modelagem Matemática podem ser desenvolvidas no Ensino de Matemática ou de Física de acordo com a dinâmica da figura 1, na próxima página. Nela, as setas de duas direções, contínuas ou não, significam que cada etapa de Modelagem 
apresenta uma conexão com as demais etapas. Já as setas de duas direções, não contínuas horizontalmente ou verticalmente, expressam que há duas possibilidades no processo de Modelagem. A primeira é que se pode fazer o levantamento e seleção dos dados e, posteriormente, a formulação do problema, enquanto a outra é fazer o processo inverso, isto é, pode-se formular o problema e depois realizar o levantamento e seleção dos dados. As $3^{\mathrm{a}}$ e $4^{\mathrm{a}}$ etapas da atividade de Modelagem são flexíveis e alteráveis, cabendo assim aos(às) professores(as), pesquisadores(as), estudantes e/ou universitários, analisar o procedimento adequado para atingir o objetivo proposto e desenvolver os conceitos matemáticos.

As duas setas pontilhadas significam que, caso a resolução do problema não seja considerada aceitável diante do processo da Modelagem, ou seja, se não for vista como satisfatória ou eficiente para resolver o problema formulado, pode-se retomar o processo a partir da atividade na $3^{\mathrm{a}}$ etapa escolhida a princípio, conforme já foi realizada, de acordo com o que já foi feito no levantamento e seleção dos dados ou na formulação do problema, para efetuar as simplificações e/ou modificações cabíveis. Também, segundo os objetivos estabelecidos e realidades escolares e/ou universitárias, uma certa atividade de Modelagem pode ser realizada de acordo com todas as etapas de sua dinâmica ou não - por exemplo, a referida atividade pode ser iniciada a partir do levantamento e seleção dos dados ou da formulação do problema, visando o ensino e aprendizagem de Matemática e/ou Física. Para tanto, observe esta figura 1:

\section{Figura 1 - Dinâmica para desenvolver o processo de Modelagem Matemática}

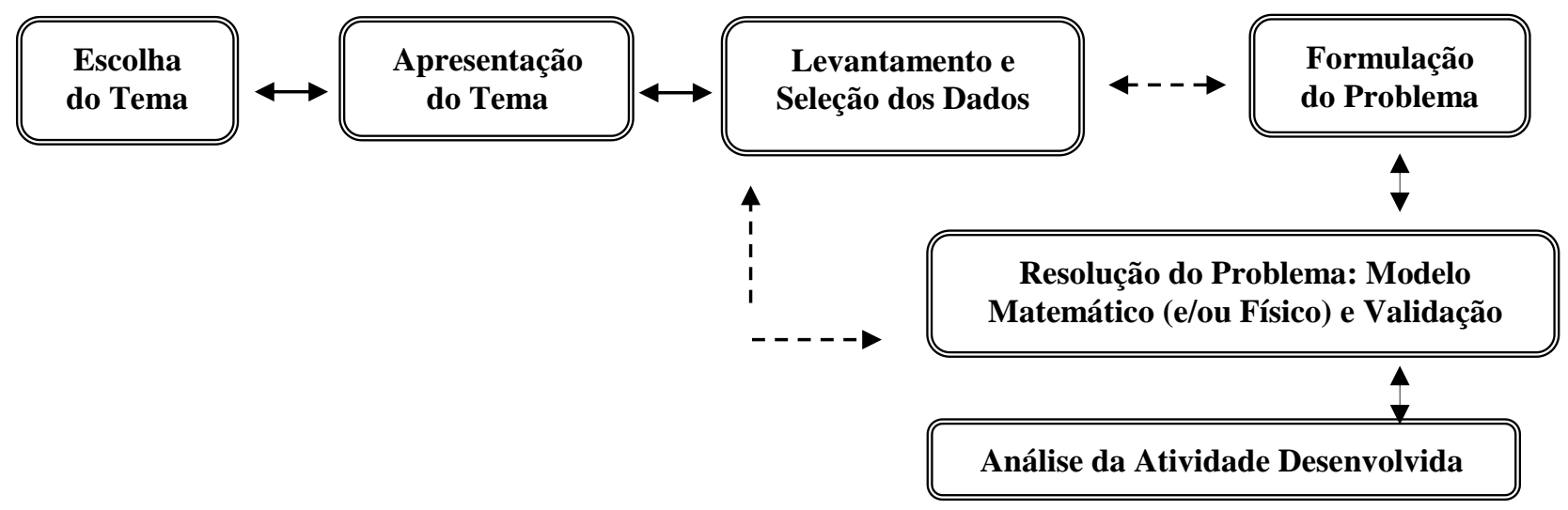

Fonte: Soares (2012a, p. 43; 2012b, p. 160).

Soares (2012a, p. 42-110, 2012b, p. 161-213) orienta e indica uma dinâmica para fazer o processo de Modelagem no Ensino de Matemática ou de Física da seguinte forma:

$\mathbf{1}^{\text {a }}$ Etapa - Escolha do Tema: É o que se pretende pesquisar e investigar. O tema a ser definido busca analisar uma situação da realidade em que se faz a formulação do problema posteriormente. O tema escolhido envolve alguma área de estudo, como saúde, meio ambiente, esporte, agricultura, agropecuária, engenharia, fenômenos, economia, política, comércio, indústria, educação, ensino, ciência, tecnologia, sociedade e universo, entre outras. Assim, inicialmente, ele não apresentará conexão direta com a Matemática ou a Física e é importante que o(a) docente e/ou os estudantes agrupados escolham um tema que desperte interesse e motivação e em relação ao qual seja fácil obter informações e dados, assim como fazer a formulação e resolução dos problemas.

Bassanezi (2009, p. 45, grifos do autor) infere que "O início de uma modelagem se faz com a escolha de temas. Faz-se um levantamento de possíveis situações de estudo as quais 
devem ser, preferencialmente, abrangentes para que possam propiciar questionamentos em várias direções". O tema escolhido é energia elétrica; este foi eleito por nós para realizar as atividades de Modelagem, pois se encontrava de acordo com os conceitos básicos a serem estudados e discutidos em ambas as turmas dos colégios. Ademais, os estudantes reconheceram sua relevância para desenvolver a referida atividade tendo em vista que a energia elétrica auxilia a vida diária das pessoas e pode se tornar esgotável em um tempo futuro.

$2^{\mathbf{a}}$ Etapa - Apresentação do Tema: É pesquisar, sintetizar e explicitar a importância do tema escolhido. Essa apresentação busca discutir e enfatizar a relevância do tema selecionado, em que se levam os estudantes ao envolvimento e à valorização, pois, quanto mais interesses e interações, maiores as possibilidades de se obter um resultado aceitável da prática. Para isso, é necessário pesquisar e investigar textos e trabalhos da área escolhida, por meio de pesquisas bibliográficas em bibliotecas físicas e/ou on-line, em livros, revistas e jornais, via pesquisas de campo e/ou entrevistas e outros meios. Isso pode ser organizado pelo(a) docente ou estudantes agrupados e ser conciso ou abrangente dependendo da natureza do tema e da disponibilidade que se tem.

Na concepção de Schmitt e Biembengut (2007, p. 6) “Assim, promover Modelagem Matemática no ensino implica também, ensinar o estudante em qualquer nível de escolaridade a fazer pesquisa, sobre um tema de seu interesse". Dessa maneira, AG investigaram e discutiram sobre os conceitos de eletricidade, energia, algumas fontes alternativas de energia, trabalho de uma força, potência, rendimento e tempo. Isso lhes possibilitou entender a relevância do tema definido para o meio social e valorizá-lo nas atividades propostas.

$3^{\text {a }}$ Etapa - Levantamento e Seleção dos Dados: É o que se pretende pesquisar, investigar e desenvolver. Conforme os objetivos propostos, conceitos matemáticos e/ou físicos a serem desenvolvidos e recursos disponíveis, pode-se fazer o levantamento e seleção dos dados e, posteriormente, a formulação do problema, ou vice-versa (podem-se inverter as $3^{\mathrm{a}} \mathrm{e} 4^{\mathrm{a}}$ etapas). Para isso, pesquisa-se fazendo um levantamento dos dados, os quais são adequados às análises qualitativas e quantitativas sobre o tema escolhido. Seguidamente, analisam-se e exploram-se os dados obtidos por meio da seleção, isto é, da simplificação dos dados mais importantes e eliminação dos menos relevantes (variáveis), com a identificação das possíveis investigações para os problemas a serem resolvidos (hipóteses) e a organização, sintetização e/ou categorização dos dados, por exemplo, em tabulação, se for necessário. Isso pode ser feito pelo(a) docente e/ou estudantes agrupados, sendo assim fundamental analisar o envolvimento e a motivação dos sujeitos para desenvolver este processo, além da preparação docente para essa orientação.

Para Bassanezi (2009, p. 46), "Os dados coletados devem ser organizados em tabelas que, além de favorecerem uma análise mais eficiente, podem ser utilizadas para a construção dos gráficos das curvas de tendências". "Aqui, o levantamento de informações, a formulação de problemas e a resolução destes cabem aos alunos. A ênfase está em estimular os alunos a identificar situações problemáticas, formulá-las adequadamente e resolvê-las" (BARBOSA, 2001, p. 54). Para orientar e mediar a aprendizagem de Física de acordo com a realidade dos AG foi preciso motivá-los e encorajá-los a investigarem e compreenderem os conceitos físicos a partir de situações concretas. Para tanto, organizamos e apresentamos esta etapa como segue:

A Copel (2008) esclarece o consumo de energia de alguns equipamentos utilizados em residências, como exibe o gráfico 1 : 
Gráfico 1 - Uso de energia elétrica nas residências

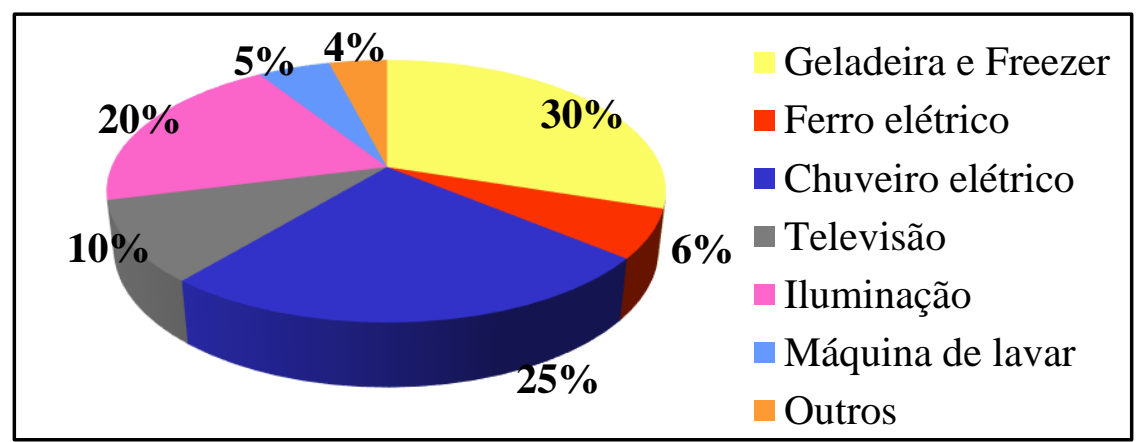

Fonte: Copel (2008).

Quadro 2 - Convencional B1 - Taxas e Tarifas

\begin{tabular}{|c|c|c|}
\hline CONVENCIONAL & \multicolumn{2}{|c|}{ Resolução ANEEL N N $^{\circ} 015$} \\
\hline & de 22 de junho de 2010 \\
\hline Tarifa em R\$ / kwh & Resolução ANEEL & $\begin{array}{c}\text { Com impostos: ICMS e } \\
\text { PIS/COFINS }\end{array}$ \\
\hline B1 - Residencial & 0,300 & 0,45816 \\
\hline Vigência em 24/06/2010 & & PIS dez 09 \\
\hline
\end{tabular}

Fonte: Copel (2010).

Os principais aparelhos que utilizam energia elétrica nas residências são a geladeira, freezer, chuveiro elétrico, iluminação, televisor, ferro elétrico, máquina de lavar roupa e louça e outros como computador, aparelhos de som e de condicionadores de ar, que são prioridades na maioria das residências. A sua utilização consciente trará resultados satisfatórios à economia do lar e, de acordo com as normas e orientação da Copel (2008), há um direcionamento sobre como utilizar de modo eficiente os eletrodomésticos sem desperdiçar energia elétrica. Assim, o consumo de energia elétrica na residência é obtido segundo o número de $\mathrm{kW} / \mathrm{h}$ consumido e o número de horas utilizado, como apresenta-se a seguir:

Para obter o valor em reais ( $\mathrm{R} \$$ ) do consumo mensal, multiplique o consumo mensal em $\mathrm{kW} / \mathrm{h}$ pelo valor da tarifa cobrada pela concessionária local:

Consumo mensal $=($ potência do equipamento em watts $\mathrm{x}$ Dias/mês $\mathrm{x}$ Hora/dia $) / 1000$

No estado do Paraná, a Copel, administradora e distribuidora de energia elétrica possibilita seus usuários o cálculo por classe. A classe residencial se enquadra tipo B1 convencional, ou seja, as famílias que não se enquadram em baixa renda, como ilustrou o quadro 2 já citado acima. Já a Agência Nacional de Energia Elétrica (ANEEL) regula e fiscaliza a produção, transmissão e comercialização de energia elétrica. Os impostos que incidem sobre o valor da fatura são o Imposto sobre Circulação de Mercadorias e Prestação de Serviços (ICMS), de competência Estadual e Federal; o Programa de Integração Social (PIS) e a Contribuição para o Financiamento da Seguridade Social (COFINS). 
A Copel (2010)3 possui um simulador de consumo de energia elétrica para diferentes produtos utilizados nas residências. Assim, houve a necessidade de simplificar e selecionar os principais equipamentos usados com frequência pelos estudantes e suas famílias. Para essa organização e investigação, foi apresentada a eles esta tabela que é de acordo com Copel (2010):

Tabela 1 - Simulador de Consumo de Energia Elétrica

\begin{tabular}{|c|c|c|c|c|c|}
\hline $\begin{array}{l}\text { Aparelhos Elétricos } \\
\text { (uma unidade) }\end{array}$ & $\begin{array}{l}\text { Potência } \\
\text { em } \\
\text { Watts }\end{array}$ & $\begin{array}{ll}\text { Dias } & \text { de } \\
\text { Uso } & \text { ao } \\
\text { Mês } & \end{array}$ & $\begin{array}{l}\text { Tempo de } \\
\text { Uso: } \\
\text { Minutos/Dia }\end{array}$ & $\begin{array}{lr}\text { Consumo } & \text { de } \\
\text { Utilização: }(\mathrm{kW} / \mathrm{h}) \text { por } \\
\text { mês }\end{array}$ & $\begin{array}{lr}\text { Custo } & \text { do } \\
\text { Consumo } & \text { por } \\
\text { Mês: } \mathrm{R} \$ & \end{array}$ \\
\hline Geladeira & 130 & 30 & 1440 & & \\
\hline Freezer & 130 & 30 & 1440 & & \\
\hline Chuveiro Elétrico & 3500 & 30 & 10 & & \\
\hline Lâmpada Fluorescente & 9 & 30 & 300 & & \\
\hline Lâmpada Incandescente & 40 & 30 & 300 & & \\
\hline Televisor & 110 & 30 & 120 & & \\
\hline Ferro Elétrico & 1000 & 30 & 60 & & \\
\hline Máquina de Lavar & 350 & 30 & 60 & & \\
\hline Alguns - Outros Produtos: & --- & --- & --- & --- & --- \\
\hline Ventilador & 120 & 30 & 480 & & \\
\hline Ar condicionado & 1000 & 30 & 480 & & \\
\hline Computador & 300 & 30 & 180 & & \\
\hline Aparelho de Som & 80 & 30 & 180 & & \\
\hline Secador de Cabelos & 1400 & 30 & 15 & & \\
\hline $\begin{array}{l}\text { Chapinha/Prancha } \\
\text { Alisadora }\end{array}$ & 1500 & 30 & 15 & & \\
\hline Forno de Micro-ondas & 1200 & 30 & 15 & & \\
\hline Telefone sem Fio & 100 & 30 & 60 & & \\
\hline Aparelho de DVD & 50 & 30 & 120 & & \\
\hline Carregador de Celular & 1,5 & 30 & 300 & & \\
\hline TOTAL & & & & & \\
\hline
\end{tabular}

Fonte: Copel (2010).

Nas atividades de Modelagem, todos os grupos analisaram o consumo de utilização em $\mathrm{kW} / \mathrm{h}$ por mês e o custo em reais do consumo por mês.

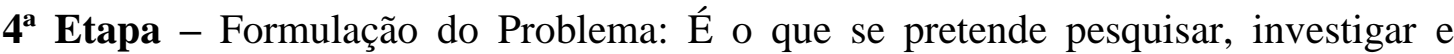
resolver. Com o levantamento e seleção dos dados sobre o tema escolhido se definem os problemas para fazer sua resolução, ou seja, os problemas são elaborados por meio dos dados que envolvem situações da realidade, de modo claro e de fácil entendimento. $\mathrm{Ou}$, ainda, primeiramente, podem-se formular os problemas e depois efetuar o levantamento e seleção dos

${ }^{3}$ COMPANHIA PARANAENSE DE ENERGIA ELÉTRICA (COPEL). 2010. Simulador de Consumo de Energia Elétrica. Disponível em: <http://www.copel.com/hpcopel/simulador/>. Acesso em: 12 ago. 2010. 
dados para fazer suas resoluções (podem-se inverter as $3^{\mathrm{a}}$ e $4^{\mathrm{a}}$ etapas). Nesta etapa, elaboramse perguntas com problematizações que tenham alguma relação com o tema selecionado, variáveis envolvidas e/ou hipóteses levantadas, as quais podem ser realizadas pelo(a) professor(a) e/ou estudantes agrupados. Assim, é essencial refletir sobre as relações existentes apresentadas nos dados organizados, sintetizados e/ou categorizados e sobre as possibilidades, para problematizar e fazer sua resolução, posteriormente.

Bassanezi (2009, p. 28) explica que "Enquanto a escolha do tema de uma pesquisa pode ser uma proposta abrangente, a formulação do problema é mais específica e indica exatamente o que se pretende resolver". Já "um problema se constitui em uma pergunta científica quando explicita a relação entre as variáveis ou fatos envolvidos no fenômeno" (BASSANEZI, 2009, p. 28). Inúmeros estudantes apresentavam resistências em formular problemas com nitidez; não estavam habituados a formular, discutir e investigar problemas, pois se voltavam à competência de resolvê-los. Com o levantamento e seleção dos dados aclarados, a professora pesquisadora expôs e discutiu os problemas com os AG em ambas as turmas de maneira independente:

- Como é possível reduzir o consumo de energia elétrica residencial?

- Qual é a relação existente entre Consumo em kW/h por mês e o Custo do Consumo em R \$ por mês? Que modelo físico (e/ou matemático) pode expressar essa relação?

Para tal, os estudantes estimaram a utilização mensal de energia elétrica consumida em quilowatt/hora $(\mathrm{kW} / \mathrm{h})$ e o custo do consumo em reais $(\mathrm{R} \$)$ por mês de alguns equipamentos usados nas residências (figura 2).

$5^{\mathbf{a}}$ Etapa - Resolução do Problema - Modelo Matemático (e/ou Físico) e Validação: É desenvolver, explorar e solucionar o problema formulado, o que permite elaborar um modelo matemático (e/ou físico) e analisar sua aceitação ou não. Com as ferramentas e recursos reais, matemáticos, físicos e/ou computacionais, o(a) docente e/ou estudantes agrupados buscam resolver o problema. O Modelo Matemático e/ou Físico é resultante da exploração, da organização e da transformação de problematizações das situações ou dos fenômenos (reais, matemáticos e/ou físicos) em linguagem matemática e/ou física, e, por meio dele, pode-se buscar a resolução, a representação e a explicitação de matematizações, visando o ensino e a aprendizagem de Matemática e/ou de Física, via processo de obtenção da solução do problema formulado. Esse modelo pode ser expresso por meio de um conjunto de símbolos, estruturas e relações matemáticas, como gráficos, tabelas, funções, sistemas, equações, diagramas, figuras geométricas, representações estatísticas e expressões matemáticas, expressões físicas, entre outros. Em sua elaboração analisam-se as hipóteses de resolução, definem-se as variáveis independentes e dependentes e também as representações adequadas para elas. Aqui, exploramse os conceitos matemáticos (e/ou físicos) que devem estar no programa da disciplina ou não, a depender dos objetivos a serem atingidos, realidades escolares e/ou universitárias, durabilidades e recursos disponíveis para realizar a atividade de Modelagem. A Validação do Modelo Matemático pode ou não ser feita, conforme a finalidade do objeto de estudo, mas é de suma importância, pois possibilita analisar a relevância ou não do modelo matemático (e/ou físico) obtido ao compará-lo com os dados (reais, matemáticos e/ou físicos). Quando o modelo matemático e/ou físico não for considerado válido, ou seja, não tiver aproximações da situação ou fenômeno que o originou, pode-se reiniciar o processo, conforme já foi feito a partir das $3^{\mathrm{a}}$ ou $4^{\text {a }}$ etapas de Modelagem (ou seja, a partir do levantamento e seleção dos dados ou da formulação do problema), para fazer ajustes na coleta dos dados, formulação dos problemas, simplificações e/ou modificações possíveis.

Segundo Batista e Fusinato (2015, p. 88), "No ensino de física, a modelagem matemática também pode instigar os alunos a investigarem problemas físicos que descrevem situações reais, procurando aproximar o conhecimento ensinado na escola do cotidiano do 
aluno". Barbosa (2001, p. 50) diz que "Nas atividades de Modelagem, o professor refaz e amplia, a todo instante, seus conhecimentos de matemática e Modelagem. A cada nova investigação, novas facetas se mostram, outros processos são feitos ou refeitos e estratégias diferentes são conduzidas". Para realizar e explorar os modelos físicos e matemáticos, os sujeitos fizeram uso de calculadora para a verificação e elaboraram diversos tipos de gráficos pelo software Excel já que este é aplicável e objetivo para trabalhar as atividades propostas. Assim, os estudantes dos grupos sanaram suas dúvidas ao desenvolverem os modelos, assessoraram outros grupos, criaram fórmulas, substituíram os dados nos modelos obtidos e desenvolveram habilidades e competências, além de concepções críticas e reflexivas e autonomia na aprendizagem.

Os estudantes receberam um material impresso sobre o consumo de eletricidade (figura 2) e a pesquisadora foi indagando-os com o propósito de investigar e resolver os problemas:

P: Dentro do quadro de uso de energia elétrica nas residências, durante um mês, qual é o consumo de cada produto em $\mathrm{kW} / \mathrm{h}$ ?

P: Considerando que as taxas e tarifas da Copel (2010) se enquadram em "Taxas e Tarifas por Classe Residencial - B1 convencional" para uma determinada família, investigue qual é o custo em $\mathrm{R} \$$ do consumo mensal de cada produto.

P: Supondo que uma família disponha de todos esses produtos, estime o consumo total em $\mathrm{kW} / \mathrm{h}$ e a quantia em $\mathrm{R} \$$ a ser paga no final do mês.

Tanto no Colégio CES quanto no CEA, os sujeitos desenvolveram as atividades de modo igual ou semelhante e, em virtude da quantidade de atividades e de grupos, optou-se por ilustrar apenas o resultado de um dos Colégios, isto é, AG4 do CES, como mostra a figura 2:

\section{Figura 2 - Estimando o consumo da eletricidade em $\mathrm{kW} / \mathrm{h}$ e o custo da residência}

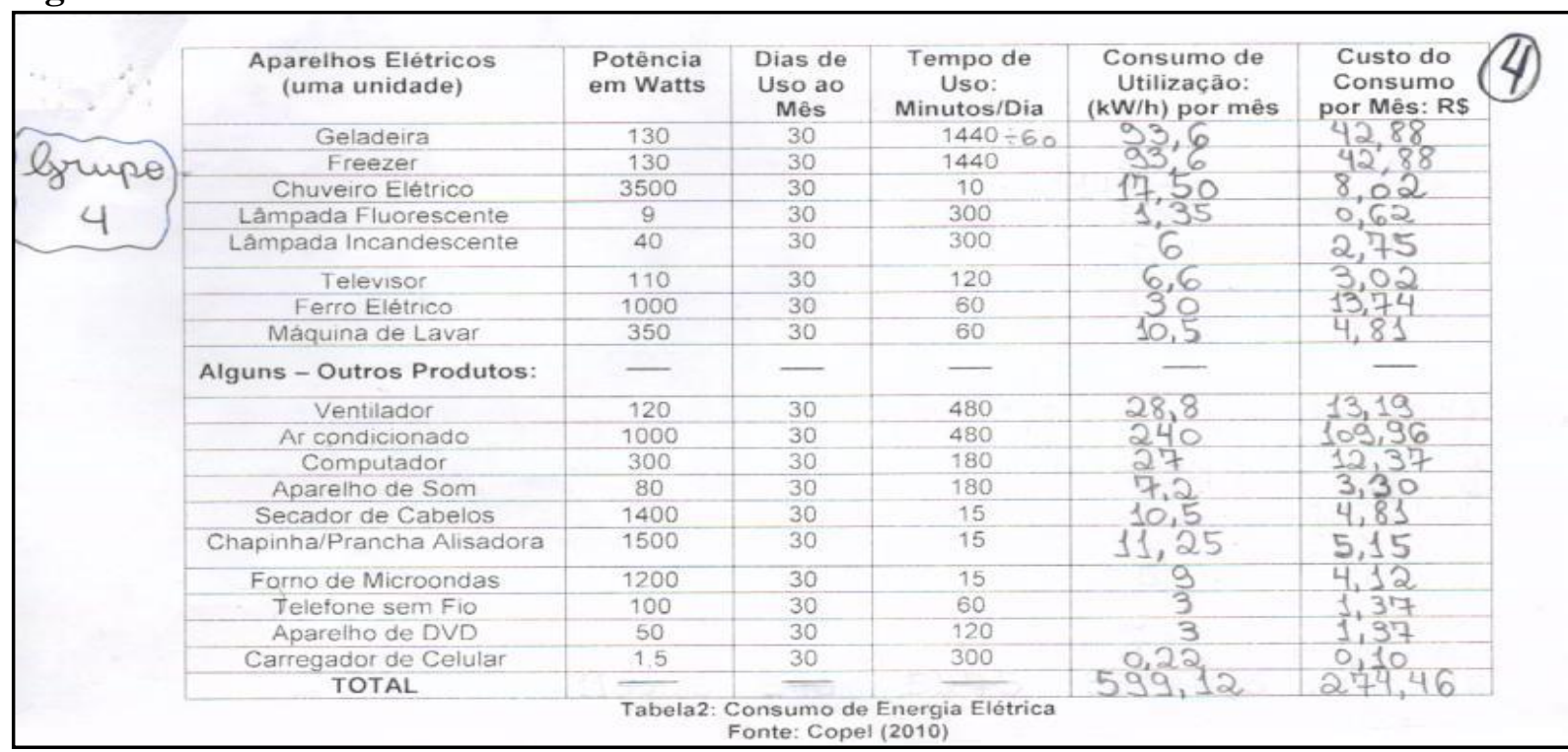

Fonte: AG4 do CES.

Quando os AG foram interrogados sobre isto: Como é possível reduzir o consumo de energia elétrica residencial?, constatou-se que a maioria deles não tinha conhecimento para estimar o consumo de energia, visto que suas concepções estavam em analisar a conta de energia para reduzir o consumo. Todavia, após realizar as atividades de Modelagem, eles admitiram que é preciso ter o conhecimento sobre o uso de energia, potência dos eletroeletrônicos, seu tipo mais eficiente, dias de utilização mensal, tempo de uso do 
equipamento e taxas e tarifas por classe segundo a concessionária local. Para analisar e resolver os problemas abordados, segue um dos que foi resolvido no Excel, figura 3:

Figura 3 - Modelo Matemático da energia elétrica mensal: cons. em $\mathbf{k W} / \mathbf{h} \times$ custo em $R \$$

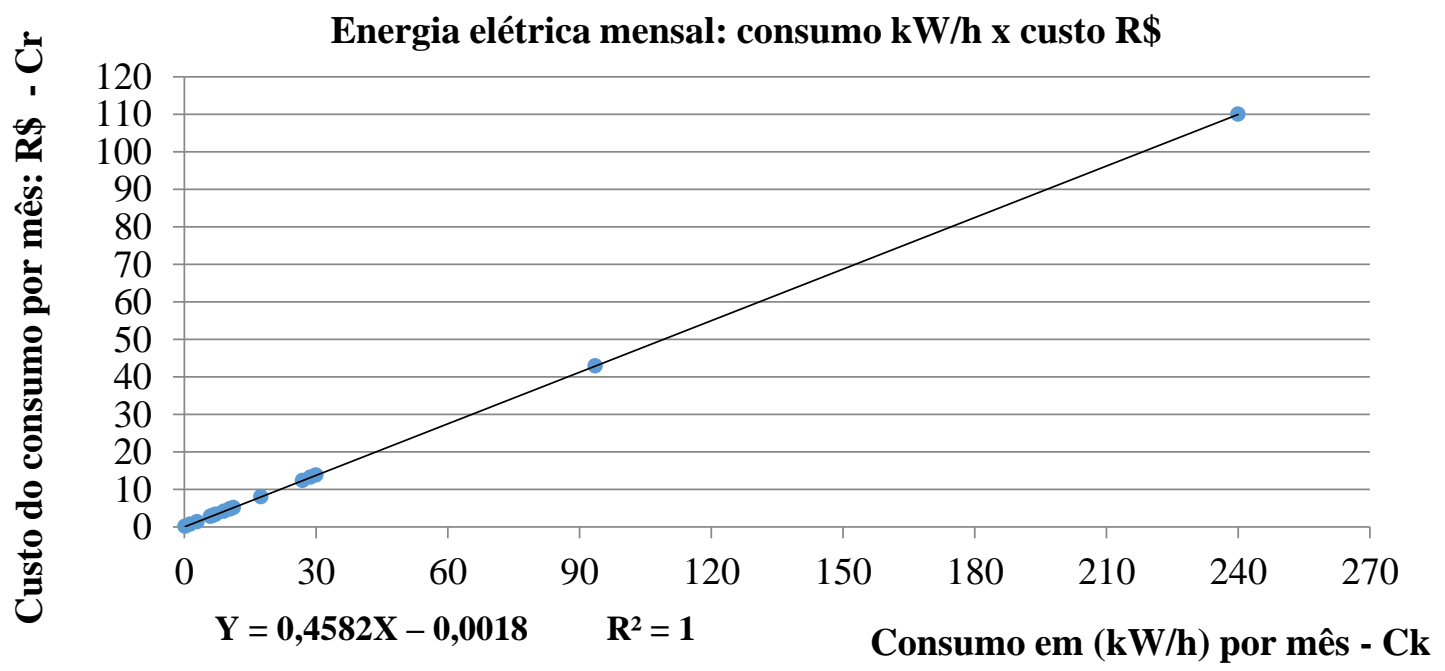

Fonte: AG1 do CEA.

A expressão obtida é uma função polinomial de primeiro grau, função afim crescente:

$$
\mathrm{y}=0,4582 \mathrm{X}-0,0018
$$

Esse modelo vai ao encontro do problema formulado ao se elucidar a relação existente entre consumo de energia em $\mathrm{kW} / \mathrm{h}$ mensal e custo em $\mathrm{R} \$$ mensal. As atividades realizadas possibilitam trabalhar de forma interdisciplinar, ou seja, ao relacionar a Física, a Matemática e as pesquisas para expressar a aplicabilidade e a importância do tema na vida dos estudantes. Isso foi executado nos contextos físico, matemático e escolar ao se analisar o consumo de energia elétrica de determinados equipamentos eletroeletrônicos usados nas residências, assim como o papel dos modelos físicos e matemáticos, simultaneamente. Além disso, os AG do CES e do CEA foram interrogados para as situações sociais e financeiras reflexivas assim:

P: Compare a diferença em $\mathrm{R} \$$ de acordo com o uso do chuveiro em dez minutos com um dos integrantes do grupo que demorou menor tempo para concluir o seu banho nesta última semana.

\section{Figura 4 - $O$ custo do uso no chuveiro}

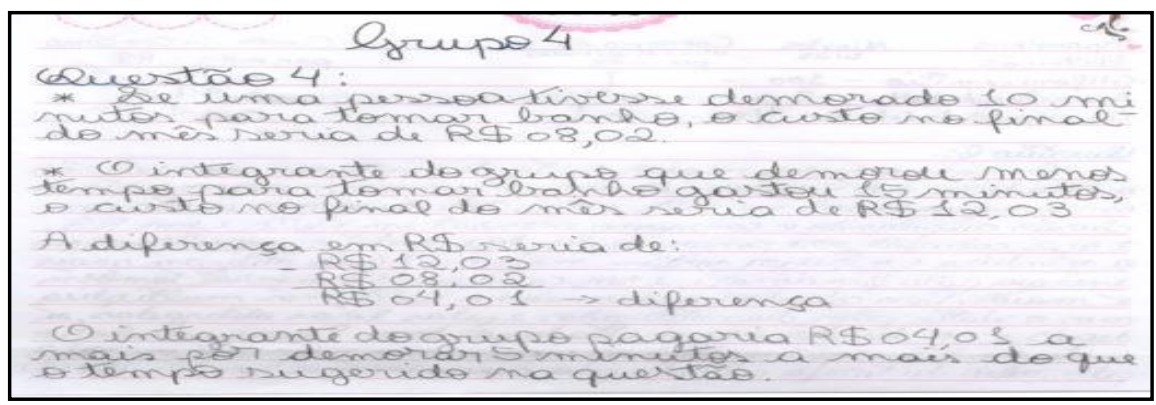

Fonte: AG4 do CES. 
Aqui, discutiram-se vários processos realizados e resultados obtidos pelos $\mathrm{AG}$ e fatores que influenciam diretamente e/ou indiretamente no consumo, tais como: desperdício de energia e de água, fazer uso do chuveiro exageradamente, questões naturais, ambientais e econômicas.

P: De acordo com os dados de uso de energia elétrica nas residências, selecione doze produtos conforme a realidade do grupo e, em seguida, estime o consumo de dez dias de uso, calcule o consumo total $\mathrm{em} \mathrm{kW} / \mathrm{h}$ e a quantia em $\mathrm{R} \$$ a ser paga no final do mês.

Nessa fase, analisaram-se e discutiram-se os processos desenrolados e os resultados obtidos pelos estudantes agrupados e os fatores pertinentes ao valor a ser pago pelo uso da energia elétrica. Tanto no CES quanto no CEA, isso foi feito de acordo com a realidade de cada grupo, uma vez que os sujeitos identificaram que a quantia em $\mathrm{R} \$$ a ser paga no final do mês pelo uso da eletricidade estava de acordo com o consumo total em $\mathrm{kW} / \mathrm{h}$ dos equipamentos elétricos. Para essa compreensão, observe a seguinte figura 5:

\section{Figura 5 - Estimando o consumo da eletricidade do grupo}

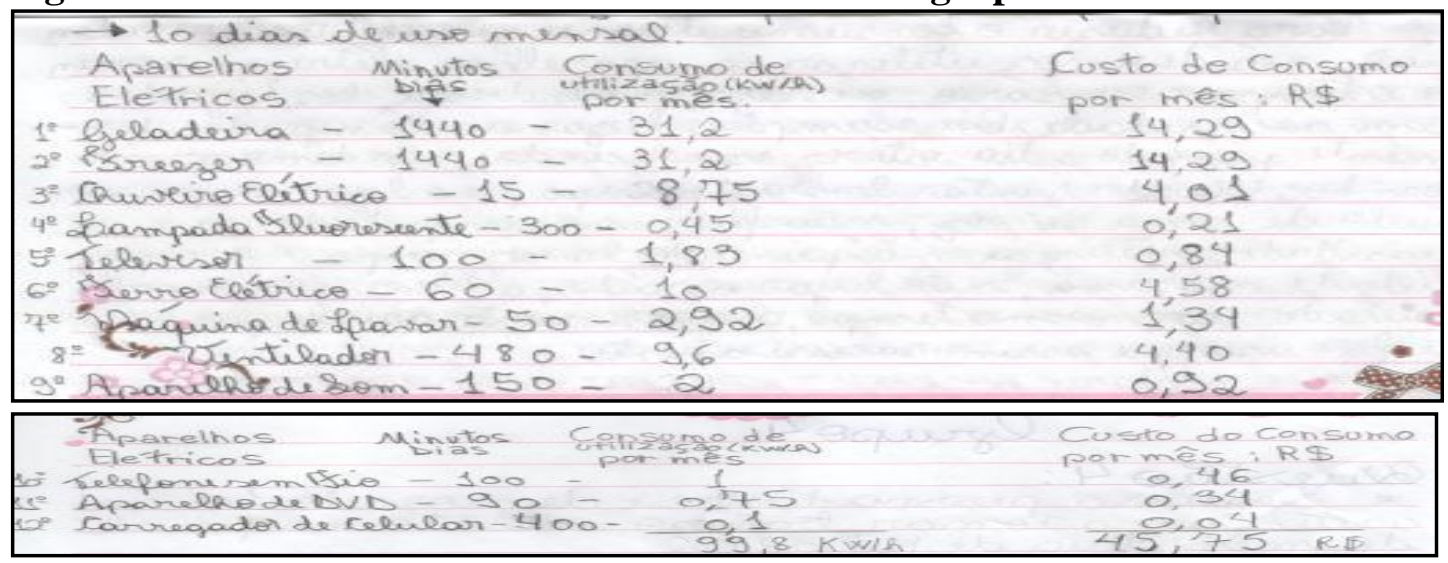

Fonte: AG4 do CES.

Nas atividades de Modelagem foram investigadas a relação existente entre o consumo de energia elétrica em $\mathrm{kW} / \mathrm{h}$ de cada equipamento e a quantia a ser paga em reais ( $\mathrm{R} \$$ ) no final do mês conforme a realidade do grupo. Assim, conforme a figura 5, ilustra-se uma atividade desenvolvida pelo grupo 4 do CES, fazendo-se uso do Excel, tal como aclara a figura 6:

\section{Figura 6 - Modelo Mat.o para a energia elétrica mensal: cons. em KW/h $x$ custo em $R$ \$}

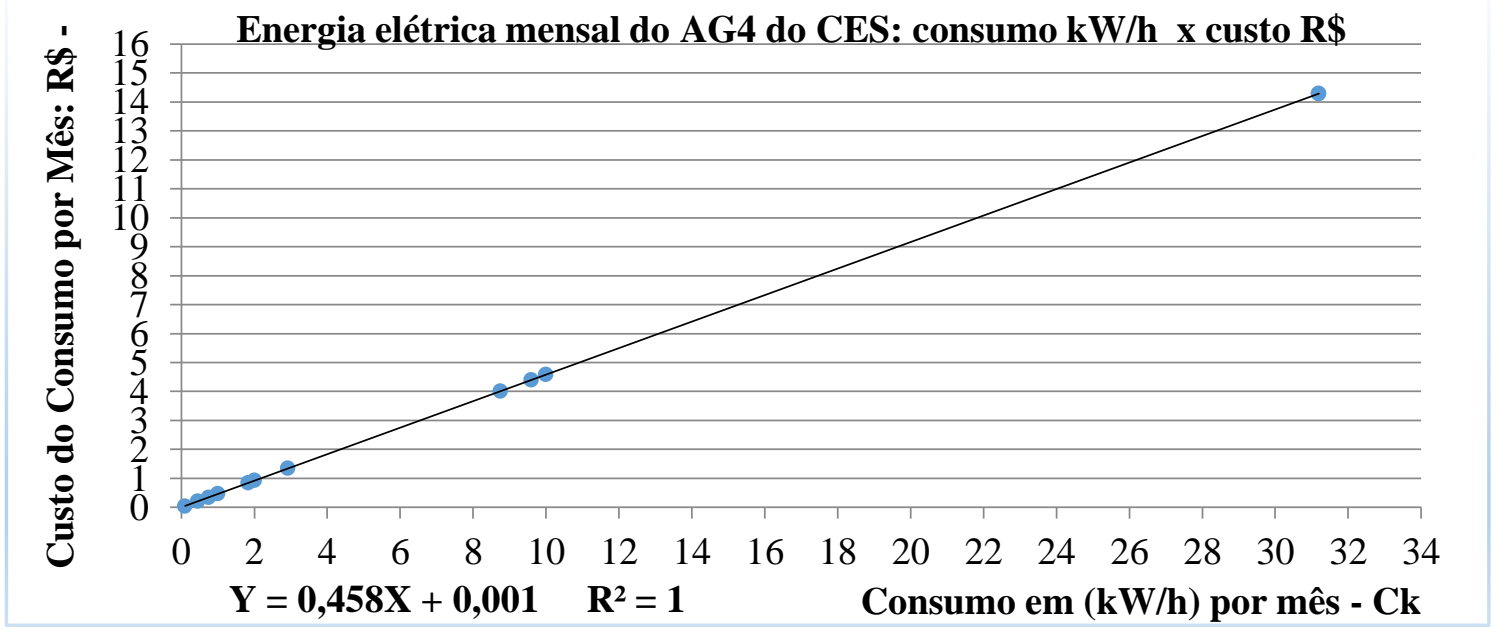

Fonte: AG4 do CES. 
O modelo matemático obtido é uma função afim crescente:

$$
\mathrm{y}=0,458 \mathrm{x}+0,001
$$

Esse modelo responde ao problema formulado ao ilustrar a relação existente entre o consumo de energia elétrica em $\mathrm{kW} / \mathrm{h}$ por mês e o custo em $\mathrm{R} \$$ por mês. Isso possibilitou interpretar e compreender a Física inserida nos contextos cotidianos e escolares de modo interdisciplinar, já que os estudantes do $1^{\circ}$ ano do Ensino Médio e do $1^{\circ}$ ano do Curso Integrado de Agropecuária devem estudar e investigar os conceitos físicos e matemáticos dessa natureza.

Os dois modelos desenvolvidos apresentam $\mathrm{R}^{2}=1$, isto é, o coeficiente de determinação para o modelo é igual a um. Assim, pode-se inferir que eles são satisfatórios aos problemas em estudo, pois há boa aproximação com os dados reais, ou seja, com dados obtidos pela concessionária de energia elétrica Copel e da realidade dos estudantes.

$6^{\mathbf{a}}$ Etapa - Análise da Atividade Desenvolvida: É explorar, discutir e evidenciar as principais considerações sobre toda a atividade de Modelagem Matemática desenvolvida. Os estudantes agrupados fazem esta análise, que pode ser descrita e/ou apresentada oralmente por meio de trabalhos, relatórios ou seminários. Aqui, analisam-se os resultados obtidos na resolução do problema, a aplicação do modelo matemático (e/ou físico) na sociedade, a importância de se pesquisar e aprender a Matemática por meio da Modelagem, os conceitos físicos e/ou matemáticos trabalhados e os desafios, resistências, vantagens e/ou contribuições que obtiveram com a prática aplicada, entre outros itens. Essa análise permite estimular o espírito crítico, reflexivo, ativo e inovador.

Temos que "A modelagem é eficiente a partir do momento que nos conscientizamos que estamos sempre trabalhando com aproximações da realidade, ou seja, estamos elaborando sobre representações de um sistema ou parte dele" (BASSANEZI, 2009, p. 24, grifo do autor). Assim, "A Modelagem eficiente permite fazer previsões, tomar decisões, explicar e entender; enfim participar do mundo real com capacidade de influenciar em suas mudanças" (BASSANEZI, 2009, p. 31 e p.177). Ademais, a "[...] Modelagem pode potencializar a intervenção das pessoas nos debates e nas tomadas de decisões sociais que envolvem aplicações da matemática, o que me parece ser uma contribuição para alargar as possibilidades de construção e consolidação de sociedades mais democráticas" (BARBOSA, 2003, p. 68). A Modelagem eficaz exige, cobra, pede, transforma e surpreende ao estudar e pesquisar uma porção da realidade não física ou não matemática para explorá-la e transferi-la fundamentalmente para a linguagem física e/ou matemática conforme os entendimentos, os enfoques e os propósitos dos investigadores.

Cada grupo apresentou um relatório sobre as atividades de Modelagem de energia elétrica realizadas e evidenciou uma consideração final. Posteriormente, todos os AG responderam um questionário pós-teste e efetuaram a apresentação oral do trabalho à turma e à pesquisadora.

\subsection{ALGUMAS CONTRIBUIÇÕES OBTIDAS POR MEIO DAS ATIVIDADES DE MODELAGEM SOBRE ENERGIA ELÉTRICA}

As atividades desenvolvidas de Modelagem sobre energia propiciaram diversas contribuições aos estudantes no seu uso e exploração, entre as quais vamos citar:

Social e Ambiental: os estudantes reconheceram a importância de agir com consciência diante dos problemas reais, como consumo e desperdício de energia elétrica, de economizar e utilizar racionalmente os recursos sustentáveis, como a energia elétrica, e naturais, como a água, 
pois são fatores essenciais para a sociedade, para a preservação do meio ambiente e para as próximas décadas e séculos.

Financeiro: A parte que mais chamou a atenção dos estudantes foi quando reconheceram a possibilidade de se beneficiarem diretamente caso fizessem economia, pois, à medida que $o$ uso da energia elétrica se tornasse menor, a família teria condições adequadas de satisfazer seus gostos. Eles notaram que, além de auxiliarem seus familiares nas economias domésticas, poderiam também aprender a Física no dia a dia e a Matemática com as contas a pagar, assim como contar com uma "grana" extra no final do mês.

Compreensão dos Conceitos: ao longo do desenvolvimento das atividades de Modelagem, um de seus objetivos foi apresentar aos estudantes a aplicação da Física a partir de uma situação da realidade. Nesse ponto foi notório o envolvimento dos estudantes a cada etapa do processo; a interação entre os grupos era bastante visível e o reconhecimento da relação entre a Matemática e a Física em situações cotidianas ficou claro aos participantes.

Entre as fundamentais análises feitas sobre as atividades de Modelagem, expostas por escrito e oralmente, optou-se por ilustrar a concepção de dois grupos, ou seja, do segundo e do quarto grupos do CES, pois tanto os sujeitos do CES como os do CEA exibiram acepções e conclusões iguais e/ou semelhantes. Seguem algumas das considerações explicitadas pelos AG2 e AG4, ambos do CES:

P: Conforme os doze produtos selecionados na questão anterior, qual destes corresponde ao maior consumo mensal? Como se chegou a esta conclusão?

- AG2 do CES: A geladeira deu o maior resultado.

- AG4 do CES: Os que possuem maior custo de consumo mensal são a geladeira e o freezer (os dois possuem o mesmo consumo em $\mathrm{kW} / \mathrm{h}$ e $\mathrm{R} \$$ ). Nós chegamos a esta conclusão analisando o consumo mensal em $\mathrm{kW} / \mathrm{h}$ e em $\mathrm{R} \$$, e após analisar esse consumo mensal dos doze produtos, percebemos que a geladeira e o freezer gastam mais em $\mathrm{kW} / \mathrm{h}$ (pois utilizam mais energia para funcionar) e seu custo em $\mathrm{R} \$$ mensal também é maior. Para obter o consumo em $\mathrm{kW} / \mathrm{h}$, nós multiplicamos os watts pelos dias utilizados e pelas horas utilizadas, aí é só dividir esse resultado por 1.000. E para obter em $\mathrm{R} \$$ é só multiplicar o consumo mensal em $\mathrm{kW} / \mathrm{h}$ pelo valor da tarifa cobrada pela concessionária local $(0,45816)$.

Os AG analisaram o consumo da geladeira ao investigar o consumo por mês de alguns dos produtos elétricos mais usados por eles e suas famílias nas residências. Assim, foram tratadas as concepções comuns dos grupos e os fatores que intervêm no consumo de energia elétrica residencial, visto que tanto os sujeitos do CES como os do CEA identificaram que, para algum produto exibir consumo elevado mensal, além de sua potência, é fundamental verificar o tempo necessário de uso. Com efeito, eles compreenderam que a potência do chuveiro elétrico é maior que a da geladeira; todavia, seu tempo de uso diário para cada pessoa corresponde a, aproximadamente, dez minutos, enquanto a geladeira não é interrompida no dia a dia em seu funcionamento, então, consequentemente, seu custo mensal é mais elevado.

De acordo com as considerações já abordadas e discutidas aqui, tem-se ainda o que proporcionou obter contribuições nas atividades de Modelagem. Para tanto, aplicou-se um questionário pós-teste e optou-se por expor as acepções dos sujeitos de apenas um dos colégios devido à quantidade de grupos, isto é, o do CEA. Isso se deu porque eles evidenciaram concepções iguais e/ou semelhantes. Em seguida, há as análises e as discussões do questionário proposto, o qual correspondeu aos seguintes questionamentos, segundo os quadros 3,4 e 5, que expõem as concepções de sujeitos de quatro grupos distintos: 


\section{Quadro 3 - Contribuições obtidas por meio das atividades de Modelagem sobre energia elétrica}

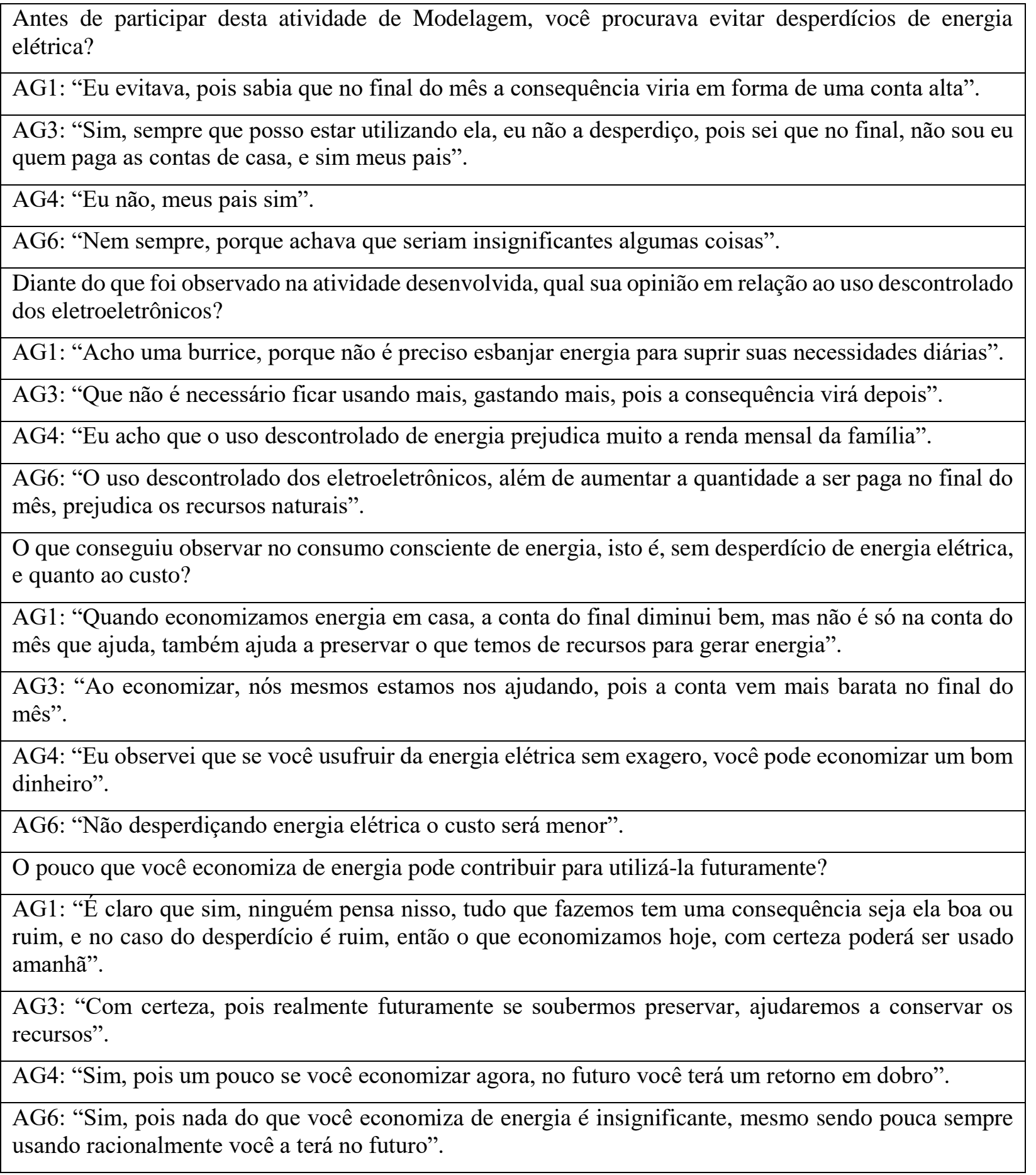

Fonte: Dados da pesquisa.

Aqui, determinados estudantes procuram evitar a utilização da energia elétrica de forma demasiada, pois têm ciência de que resultaria em fatura alta no término do mês. Contudo, eles não se incomodam com os problemas que o uso desenfreado desse recurso pode trazer ao meio ambiente. Desse modo, eles aclaram tal prática de maneira crítica em virtude da ciência de que é possível utilizar os eletroeletrônicos sem "desperdiçar", já que usam uma forma de energia com alto custo. Na concepção deles, caso não haja esbanjo de energia elétrica, é possível obter economia e favorecer a preservação dos recursos necessários para sua geração, uma vez que 
isso permite a contribuição para si mesmos e para as pessoas, diretamente e indiretamente, assim como para as futuras gerações. Com efeito, os estudantes passam a ter criticidade, visto que a energia economizada é vista como um fator fundamental para as próximas décadas, embora este não seja o entendimento da maioria das pessoas. Na sequência há o quadro 4:

\section{Quadro 4 - Contribuições obtidas por meio das atividades de Modelagem sobre energia elétrica}

Em sua opinião, nós precisamos nos preocupar com o uso da energia para o futuro?

AG1: "Precisamos, porque uma das maiores fontes usada para a produção de energia é a água e se um dia ela acabar, qual recurso que temos em abundância pode ser usado para suprir sua falta?".

AG3: "Sim, pois para gerar energia, muitas vezes nas hidrelétricas se usa água (doce). Se não preservarmos ou economizarmos como ficará?".

AG4: "Sim, pois para gerar energia é preciso de água, e como todos nós sabemos que a água está acabando, temos que economizar tanto na energia elétrica como no consumo de água".

AG6: "Sim, pois os recursos naturais futuramente não darão mais para sustentar a energia das cidades".

As pessoas têm o direito de fazer uso de energia indiscriminadamente como quiserem desde que possam pagá-la no final do mês?

AG1: "É, vai de como cada pessoa leva em conta a questão do desperdício, fica a critério de cada um contribuir ou não, independente se ela poderá pagar".

AG3: "Sim, mas tem que saber economizar".

AG4:"Sim, mas desde que não exagere e tenha consciência de que isto pode trazer consequência no futuro".

AG6: "Infelizmente o uso de energia não é controlado, podendo assim as pessoas usar quando e quanto quiser, mas se elas tivessem consciência talvez fizessem diferente".

Manter nosso padrão de vida e o conforto que a energia elétrica proporciona é mais importante que os recursos naturais gastos para gerar essa energia?

AG1: "Acho que entre as duas coisas têm que se haver um equilíbrio, deixar de usar a energia no dia a dia é quase impossível, e os recursos naturais são importantíssimos".

AG3: "Não, pois todos esses recursos nem sempre estarão pra sempre, então se não preservarmos, no futuro não terão eles".

AG4: "Não, eu acho que seria melhor se pudéssemos ter os dois sem prejudicar o meio ambiente".

AG6: "Não, seria sustentável se houvesse um equilíbrio entre conforto e recursos naturais".

Não é melhor reduzir o consumo de energia elétrica, a correr o risco de ficar sem ela em nossas residências?

AG1: "Sim, mas o difícil é todo mundo aceitar essa condição; em minha opinião vale muito a pena".

AG3: "Vale sim, mais nem todos pensam deste modo, pois por mim vale a pena".

AG4: "Vale muito a pena, pois nosso futuro está em risco".

AG6: "Sim, pois assim você e o meio ambiente seriam beneficiados".

Fonte: Dados da pesquisa.

No quadro 4, há uma inquietação com o consumo da energia elétrica e da água, pois a quantidade e a qualidade desses bens são inquietantes a cada ano que passa, já que novos alertas 
são apresentados pelos responsáveis. Entretanto, alguns sujeitos afirmavam que não há razões para se incomodarem com a natureza e seus recursos. Por outro lado, vários deles alegavam que as pessoas podem fazer uso da energia elétrica infindavelmente, pois as concessionárias de energia não controlam a utilização de energia das pessoas, só se interessam com o recebimento da fatura. Em compensação, defendiam a utilização consciente da energia, já que isso é fundamental para o meio ambiente e o meio econômico.

Apesar de a energia elétrica ser vital o dia a dia, esta necessita dos recursos naturais para sua geração. Isto viabilizou aos AG entenderem que é preciso haver um equilíbrio entre energia e consumo para não haver danos ao meio ambiente e ao longo da vida dos seres humanos. Todos eles chegaram à mesma conclusão de que é "impossível" não utilizar a energia elétrica cotidianamente; contudo, é necessário usá-la com discernimento, caso contrário, futuramente sofreremos as consequências, sejam elas positivas ou não. Em seguida, observe o quadro 5:

\section{Quadro 5 - Contribuições obtidas por meio das atividades de Modelagem sobre energia}

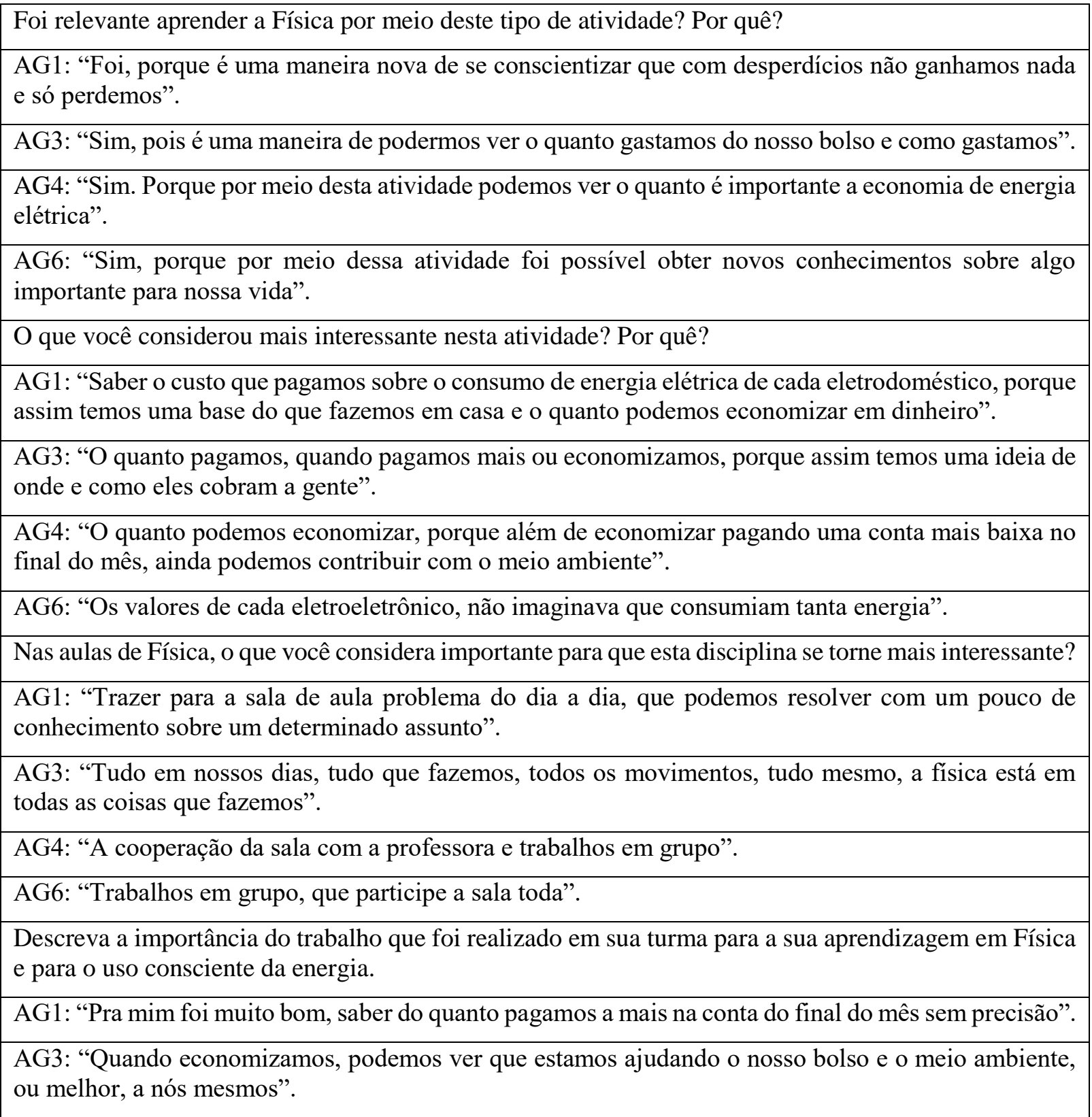


AG4: "Ter conhecimento e consciência daquilo que está fazendo".

AG6: "Ter consciência".

Fonte: Dados da pesquisa.

AG ao realizarem atividades por meio da Modelagem no ensino de Física souberam pensar e aprender a partir de problemas da realidade, o que proporcionou momentos de reflexões no que se refere à energia elétrica, bem como seus desperdícios e implicações sociais. Eles identificaram o processo de Modelagem sobre e por meio das atividades de energia elétrica e compreenderam conceitos da Física ao fazer uso desta estratégia de ensino e aprendizagem, pois foram analisadas situações concretas do dia a dia e do contexto escolar deles.

Nesse contexto, eles compreenderam a relevância de se investigar e resolver situaçõesproblema do dia a dia com o apoio da Modelagem. Isso porque foram envolvidos os problemas de sua vivência e também teve relação com o fato de as ações terem sido desenvolvidas em grupo, o que permitiu uma discussão a respeito do assunto, deixando nítida a importância de haver cooperação da turma para a execução das atividades propostas, o que conscientizou o grupo de que juntos se tornam eficientes e revolucionados.

\subsection{ALGUNS CONCEITOS FÍSICOS E MATEMÁTICOS ABORDADOS NAS ATIVIDADES DE MODELAGEM}

No transcorrer das atividades propostas de Modelagem foi possível discutir questões ambientais, sociais e econômicas, como as taxas e tarifas de energia da ANEEL, as taxas e tarifas com impostos como ICMS e PIS/COFINS, a geração e a produção de energia diante de seus recursos naturais, o uso consciente da energia e o consumo exagerado e suas consequências, tanto financeiras quanto ao meio ambiente. Nelas, foi possível explorar os conceitos físicos e matemáticos, simultaneamente, como mostra o quadro 6:

Quadro 6 - Noções dos conceitos Físicos e Matemáticos desenvolvidos nas Atividades de Modelagem

\begin{tabular}{|c|c|}
\hline Conceitos Físicos & O que foi desenvolvido nas atividades \\
\hline Energia & $\begin{array}{l}\text { - Eletricidade e energia; } \\
\text { - Fontes alternativas de energia: hídrica, térmica, elétrica, marés, solar, eólica, } \\
\text { nuclear, biomassa, geotérmica e fóssil; e Energia elétrica consumida em KW/h e } \\
\text { R\$; } \\
\text { - Trabalho de uma força; potência; rendimento; e tempo. }\end{array}$ \\
\hline $\begin{array}{l}\text { tos } \\
\text { ticos }\end{array}$ & O que foi discutido/explorado nas atividades \\
\hline Estatística & $\begin{array}{l}\text { - Análise, interpretação e compreensão dos dados; } \\
\text { - Construção e análise de tabelas e gráficos no Excel e/ou caderno; } \\
\text { - Levantamento e seleção dos dados; e Formulação dos problemas; } \\
\text { - Identificação das possíveis investigações dos problemas (hipóteses); } \\
\text { - Organização de informações e dados em tabelas e gráficos no Excel e/ou } \\
\text { caderno; } \\
\text { - Simplificação das informações e dados (variáveis). }\end{array}$ \\
\hline
\end{tabular}




\begin{tabular}{|l|l|}
\hline \multirow{1}{*}{$\begin{array}{c}\text { Geometria } \\
\text { Analítica }\end{array}$} & - Coeficiente angular e linear da reta; \\
& - Sistema Cartesiano Ortogonal: \\
& * Plano cartesiano e seus quadrantes, par ordenado e coordenada; \\
& * Intersecção das retas x e y (origem). \\
\hline Números & $\begin{array}{l}\text { - Naturais: Operações com números inteiros; Racionais: Operações com números } \\
\text { decimais. }\end{array}$ \\
\hline Matrizes & Representação genérica da matriz - consumo de energia tabulado. \\
\hline \multirow{3}{*}{ Funções } & $\begin{array}{l}\text { - Domínio e imagem da função (variável independente - x) e (variável dependente } \\
\text { - y); }\end{array}$ \\
& $\begin{array}{l}\text { - Funções polinomiais do } 1^{\circ} \text { grau e seus gráficos; - Função afim, crescente e } \\
\text { decrescente. }\end{array}$ \\
\hline
\end{tabular}

Fonte: Dados da pesquisa.

\section{CONSIDERÇÕES FINAIS}

Este artigo apresenta e discute as contribuições obtidas por meio das atividades de Modelagem sobre energia elétrica no Ensino de Física, sendo efetivadas em dois colégios estaduais do Paraná: $1^{\circ}$ ano do Ensino Médio e $1^{\circ}$ ano do Curso Integrado de Agropecuária. Isso é resultante de uma pesquisa desenvolvida pela presente pesquisadora, em que esta atuava como docente nas duas turmas. Nele, o objetivo proposto foi atingido ao se trazer uma abordagem da Modelagem no âmbito das discussões e análises e tendo por focos a organização, a exploração e a explicitação de etapas de Modelagem nas atividades de energia elétrica. Isso foi feito segundo uma orientação de procedimentos aplicados com os sujeitos em sala de aula, em trabalhos extraclasse e numa articulação disso.

Nas atividades desenvolvidas de Modelagem, o tema energia elétrica partiu da realidade dos sujeitos e do contexto escolar, os quais permitiram trabalhar de modo interdisciplinar, ou seja, relacionar a Física, a Matemática e as pesquisas específicas do tema escolhido para apresentar e explorar a aplicabilidade e a importância. Com efeito, as atividades se concretizaram buscando-se discutir e entender principalmente os conceitos físicos e contribuir para a melhoria do ensino e aprendizagem de Física, a qual se utiliza de conceitos matemáticos.

As atividades de Modelagem se conduziram e se concretizaram levando em consideração os gastos de energia nos aparelhos eletrodomésticos, bem como a potência, o tempo de uso e o valor a ser pago pela fatura. No término delas, AG relacionaram os conceitos físicos e o consumo de energia elétrica dos aparelhos residenciais matematicamente. Eles observaram que o consumo do aparelho está relacionado à potência do equipamento e ao tempo de uso, visto que o valor da fatura pode ser diminuído se os aparelhos forem usados conscientemente.

Elas permitiram incentivar os estudantes para trabalharem em grupos, obterem novas experiências e aprendizagens, trabalharem com a Física a partir de situações concretas, temas sociais e de interesse da turma, resolverem problemas, obterem modelos físicos e/ou matemáticos e analisarem de modo crítico a atividade desenvolvida. Assim, eles receberam oportunidades para o estudo do comportamento do consumo e conscientização do uso racional dos eletroeletrônicos e da relação de custo e desperdício, as quais propiciaram reconhecer as possibilidades de redução e contribuição ao consumo de energia elétrica residencial.

Portanto, as atividades realizadas sobre energia elétrica por via da Modelagem Matemática propiciaram contribuições aos sujeitos em termos sociais, ambientais, financeiros e conceitos estudados e pesquisados, pois eles evidenciaram a relevância do uso racional da 
energia elétrica e seu uso consciente cotidianamente. Isso contribui para si próprios, suas famílias, futuras gerações, recursos de sustentabilidade e de natureza, economia e meios social e ambiental, assim como aos desenvolvimentos sustentáveis e naturais, tanto a curto quanto a longo prazo. Essas atividades permitiram desenvolver a ciência do saber pensar e agir diante dos problemas reais, como consumo, desperdício, sustentabilidade, economia, custo e benefício, reconhecer suas consequências e refletir sobre os deveres com e na sociedade.

\section{REFERÊNCIAS}

ALMEIDA, L. M. W.; FERRUZZI, E. C. Uma Aproximação Socioepistemológica para a Modelagem Matemática. Alexandria, Florianópolis, v. 2, n. 2, p. 117-134, 2009.

ANDRÉ, M. E. D. A. Etnografia da Prática Escolar. 2. ed. Campinas: Papirus, 1998.

BARBOSA, J. C. O que pensam os professores sobre a Modelagem Matemática? Zetetiké, Campinas-SP, Unicamp, v. 7, n. 11, p. 67-85, 1999.

BARBOSA, J. C. Modelagem Matemática: concepções e experiências de futuros professores. 2001. 253 f. Tese (Doutorado em Educação Matemática) - Programa de Pós-Graduação stricto sensu em Educação Matemática, Universidade Estadual Paulista Júlio de Mesquita Filho de Rio Claro, Rio Claro, 2001.

BARBOSA, J. C. Modelagem Matemática na Sala de Aula. Perspectiva, v. 27, n. 98, p. 65-74, 2003.

BASSANEZI, R. C. Ensino-aprendizagem com modelagem matemática: uma nova estratégia. 3. ed. São Paulo: Contexto, 2009.

BATISTA, M. C.; FUSINATO, P. A. A utilização da modelagem matemática como encaminhamento metodológico no ensino de física. Revista de Ensino de Ciências e Matemática, São Paulo, v. 6, n. 2, p. 86-96, 2015.

BOGDAN, R.; BIKLEN, S. Investigação Qualitativa em Educação: uma introdução à teoria e aos métodos. Porto: Porto Editora, 1994.

BONJORNO, J. R.; Ramos, C. M. Física: história \& cotidiano. vol. único, 2. ed. São Paulo: FTD, 2005.

BRANDÃO, R. V.; ARAUJO, I. S.; VEIT, E. A. Um estudo de caso para dar sentido à tese de que a modelagem científica pode ser vista como um campo conceitual. Revista Electrónica de Investigación en Educación en Ciencias, Buenos Aires, v. 9, n. 1, p. 1-21, 2014.

COMPANHIA PARANAENSE DE ENERGIA (COPEL). O uso eficiente de energia na sua casa. 11 ago. 2008. Disponível em: <http://www.copel.com/hpcopel/root/nivel2.jsp?endereco $=\% 20 \% 2$ Fhpcopel\%\%202Froot $\% 2 F p a g c o p e l 2 . n s f \% 2 F 0 \% 2 F 9 C 83 B 5131$ AF54B1B032573EC 005D8B0D>. Acesso em: 10 ago. 2010.

COMPANHIA PARANAENSE DE ENERGIA (COPEL). Residencial: consumo de energia. 2010. 2014. Disponível em: <http://www.copel.com/hpcopel/residencial/consumoEnergia.jsp

>. Acesso em: 04 mar. 2014.

COMPANHIA PARANAENSE DE ENERGIA (COPEL). Simulador de Consumo de Energia Elétrica. 2010. 2014. Disponível em: <http://www.copel.com/hpcopel/simulador/>. Acesso em: 05 mar. 2014. 
COMPANHIA PARANAENSE DE ENERGIA (COPEL). Taxas e Tarifas. Tarifa por classe: residencial - B1 convencional. 26 jul. 2010. Disponível em: <http://www.copel.com/hpcopel/ root/nivel2.jsp?endereco=\%2Fhpcopel\%2Froot $\% 2$ Fpagcopel2.nsf\%2F5d546c6fdeabc9a1032 571000064b22e\%2Fe3a5cb971ca23bf503257488005939ba>. Acesso em: 10 ago. 2010.

DAROIT, L.; HAETINGER, C.; DULLIUS, M. M. O ensino de fenômenos físicos através da modelagem matemática. In: X ENCONTRO GAÚCHO DE EDUCAÇÃO MATEMÁTICA. Anais... Ijuí, UNIJUI, 1-8. 2009.

DENZIN, N. K.; LINCOLN, Y. S. A disciplina e a prática da pesquisa qualitativa. In: N. K. Denzin; Y. S. Lincoln (Orgs). O planejamento da pesquisa qualitativa: teorias e abordagens. 2 ed. Porto Alegre: ARTMED, 2006.

GASPAR, A. Compreendendo a Física. Mecânica. v. 1. São Paulo: Ática, 2010.

LINCOLN, Y. S.; GUBA, E. G. Naturalistic Inquiry. Newbury Park: Sage, 1985.

LÜDKE, M.; ANDRÉ, M. E. D. A. Pesquisa em educação: abordagens qualitativas. São Paulo: EPU, 2012.

MILES, M. B.; HUBERMAN, A. N. Qualitative Data Analysis: an expanded sourcebook. 2. ed. Thousand Oaks: Sage, 1994.

PONTE, J. P. da. Estudo de caso em educação matemática. Universidade de Lisboa, Bolema, São Paulo, v. 19, n. 25, p. 1-23, 2006, Seção Especial.

ROSA, C. W. Da; FILHO, J. de P. A. Evocação espontânea do pensamento metacognitivo nas aulas de Física: estabelecendo comparações com as situações cotidianas. Investigações em Ensino de Ciências, Instituto de Física, UFRGS, Porto Alegre, v. 17, n. 1, p. 7-19, 2012.

SETTI, E. J. K.; SCHWERTNER, A. E.; DEPARIS, D. M.; Turra, F. F. R.; VERTUAN, R. E. Modelagem Matemática e Física: uma experiência com foguetes. In: XII ENCONTRO NACIONAL DE EDUCAÇÃO MATEMÁTICA. Anais... São Paulo, ENEM, 1-12, 2016.

SCHMITT, A. L. F.; BIEMBENGUT, M. S. Mapeamento das pesquisas sobre modelagem matemática no cenário mundial: análise dos trabalhos no $14^{\circ}$ grupo de estudo do Comitê Internacional de Educação Matemática - Study Group, 14 - ICMI. Revista Dynamis, Blumenau, v. 7, n. 1, p. 1-17, 2007.

SOARES, M. R. Caderno pedagógico: modelagem matemática como estratégia de ensino e aprendizagem: uma perspectiva à luz dos futuros professores de matemática. 120f. Material instrucional - Produção Técnica. Programa de Pós-Graduação stricto sensu em Ensino de Ciência e Tecnologia, Universidade Tecnológica Federal do Paraná, Ponta Grossa, 2012a.

SOARES, M. R. Modelagem matemática como estratégia de ensino e aprendizagem: uma perspectiva à luz dos futuros professores de matemática. 312f. Dissertação (Mestrado em Ensino de Ciência e Tecnologia) - Programa de Pós-Graduação stricto sensu em Ensino de Ciência e Tecnologia, Universidade Tecnológica Federal do Paraná, Ponta Grossa, 2012b.

TOMAZ, V. S.; DAVID, M. M. M. S. Interdisciplinaridade e aprendizagem da Matemática em sala de aula. 3. ed. Belo Horizonte: Autentica, 2013.

\section{Agradecimentos}

À Coordenação de Aperfeiçoamento de Pessoal de Nível Superior (CAPES), Brasil, pelo apoio financeiro parcial concedido à bolsa de estudos para cursar o doutorado no Programa de PósGraduados em Educação Matemática na Pontifícia Universidade Católica de São Paulo. 